\title{
Predicting the optimal minimal cuff volume of the laryngeal mask airway from physical examination parameters
}

\section{Go Eun Bae, Hye Won Shin, Hyong Hwan Lim, Bum Jun Ju, and Yoo Kyung Jang}

Received May 18, 2017

Revised July 26, 2017

Accepted July 26, 2017

\section{Corresponding author}

Hye Won Shin, M.D., Ph.D. Department of Anesthesiology and Pain Medicine, Korea University College of Medicine, 73 Inchonro 8-gil, Seongbuk-gu, Seoul 02841, Korea

Tel: 82-2-920-5632

Fax: 82-2-928-2275

E-mail: drhwshin@naver.com
Department of Anesthesiology and Pain Medicine, Korea University College of Medicine, Seoul, Korea

Background: Head and neck anatomy affects the laryngeal mask airway (LMA) cuff volume. The purpose of this study was to identify physical parameters that can be standardized to predict LMA cuff volume and measure the optimal and minimal LMA cuff volume in adults.

Methods: The predictors of volume or pressure of the LMA cuff were investigated in 167 patients. Manufacturers recommend a maximal cuff pressure (MCP) (i.e., $40 \mathrm{ml}$ for size $5,30 \mathrm{ml}$ for size 4), an optimal cuff volume (OCV) at a cuff pressure of $60 \mathrm{cmH}_{2} \mathrm{O}$, and a minimal cuff volume (MCV) just before audible air leakage. The physical parameters measured included height, weight, body mass index, modified Mallampati classification (MMP), neck circumference, neck length, and thyro-mental distance. Data were analyzed by stepwise multilinear analysis.

Results: The regression equations (REs) were as follows: OCV $(1.2+[0.1 \times$ height $]+$ [0.5 $\times$ neck length]); MCV for men $(-35.7+[0.25 \times$ height $]+[0.7 \times$ neck length $]-[4.1$ $\times$ MMP $]) ;$ and MCV for women $(-42.5+[0.27 \times$ height $]+[0.75 \times$ neck length $]-[2.5$

$\times$ MMP]). The mean values were as follows: MCP $>200 \mathrm{cmH}_{2} \mathrm{O}$, minimal cuff pressure $<20 \mathrm{cmH}_{2} \mathrm{O}$, OCV of $24.7 \mathrm{ml}$ for men and $15.9 \mathrm{ml}$ for women, and MCV of $12.1 \mathrm{ml}$ for men and $7.1 \mathrm{ml}$ for women.

Conclusions: LMA cuff volume is estimated from the patient's height, neck length, and MMP. The RE for calculating the MCV shows a high correlation with height, neck length, and MMP.

Key Words: Airway management, Laryngeal masks.

\section{INTRODUCTION}

The laryngeal mask airway (LMA) is widely used during anesthesia and emergency situations. It is comprising an airway tube with a large balloon cuff. Generally, LMA cuff pressure is not routinely monitored in clinical practice. The cuff pressure of LMA should be maintained under $60 \mathrm{cmH}_{2} \mathrm{O}$, the critical perfusion pressure of the pharyngeal mucosa [1], to prevent related airway morbidity that ranges from a sore throat to more serious complications such as vocal cord paralysis [2-4].

LMA manufacturers recommend only the maximal cuff volume (i.e., $40 \mathrm{ml}$ for size 5, $30 \mathrm{ml}$ for size 4) and do not provide the optimal or minimal cuff volumes required to provide a sufficient pharyngeal sealing. Furthermore, clinicians appear to regard the maximal cuff volume as a recommendation only and tend to inflate the cuff to its maximal volume, as

This is an Open Access article distributed under the terms of the Creative Commons Attribution Non-Commercial License (http://creativecommons.org/licenses/by-nc/4.0) which permits unrestricted non-commercial use, distribution, and reproduction in any medium, provided the original work is properly cited. 
illustrated in several studies [5-7]. However, to the best of our knowledge, there have been no studies on the optimal cuff volume of LMA at a cuff pressure of $60 \mathrm{cmH}_{2} \mathrm{O}$.

The anatomy of the head and neck, including the uvula, tongue, palate, pharynx, larynx, and mandible, affects LMA cuff volume. We established the following parameters from physical examinations that are useful for predicting the shape of the oropharynx: height, weight, body mass index (BMI), modified Mallampati classification (MMP), neck circumference, neck length, and thyro-mental distance with a reference to the study for obstructive sleep apnea [8].

The objective of this study was an evaluation of the physical parameters involving the head and neck that could be standardized to predict the cuff volume of LMA and measure the optimal and minimal cuff volumes of LMA in adults. Furthermore, we measured the maximal LMA cuff pressure in adults who were undergoing general anesthesia.

\section{MATERIALS AND METHODS}

\section{Study design}

Following the approval of this study by the Institutional Research Ethics Committee of our hospital (ED15263), written informed consent was obtained from all study patients. We enrolled 170 adults ( 85 men and 85 women) with American Society of Anesthesiologists grades I-II, who were between the ages of 19 and 65 years and undergoing elective general anesthesia. Patients with laryngo-tracheal pathology, a history of head and neck surgery, and a high risk of pulmonary aspiration were excluded. All the tests were performed by one of two anesthesiologists; one of the anesthesiologists performed the physical examination, and the other, who was blinded to the results of the physical examination, inserted the LMA and measured the cuff pressure.

After premedication with glycopyrrolate $0.2 \mathrm{mg}$ and midazolam $2.0 \mathrm{mg}$ intravenously, $1 \mathrm{~h}$ before their arrival in the operating room, patients were monitored by pulse oximetry, noninvasive blood pressure, electrocardiography, and the bispectral index. Anesthesia was induced with propofol $2.0 \mathrm{mg}$, rocuronium $0.6-0.9 \mathrm{mg} / \mathrm{kg}$, and remifentanil $1 \mu \mathrm{g} /$ $\mathrm{kg}$ intravenously for LMA insertion. The size of LMA (LMA classic $^{\mathrm{TM}}$, Teleflex, USA) was selected according to the patient's sex (size 5 for men and size 4 for women) $[9,10]$. Prior to insertion, LMA cuff was deflated, and a water-soluble gel was applied to its dorsal surface. The insertion of LMA was performed according to the manufacturer's instructions [11]. The head and neck were positioned similarly to that for normal tracheal intubation. We used a non-compressible pillows of heights $5.0 \mathrm{~cm}$ when the patient was lying down. The neck remained flexed, and the head was extended by pushing it from behind with one hand while inserting the mask into the mouth with the other. LMA was pushed backward while maintaining pressure against the palate and inserted until resistance was felt. The cuff was inflated using a $50 \mathrm{ml}$ syringe with a commonly administered volume, as reported by Brimacombe and Keller [9] (15 ml for size 4, $20 \mathrm{ml}$ for size 5).

If LMA insertion failed after two attempts, the airway was maintained via endotracheal intubation. The adequacy of an effective airway was evaluated by normal symmetric thoracoabdominal movement and a square-wave capnography trace. During the LMA cuff pressure and volume measurements, the anesthesia was maintained with sevoflurane $3.0-4.0 \mathrm{vol} \%$, $\mathrm{O}_{2} 6.0 \mathrm{~L} / \mathrm{min}$, and remifentanil $0.1-0.3 \mu \mathrm{g} / \mathrm{kg} / \mathrm{min}$. The lungs were ventilated using the pressure or volume controlled mode with a fresh gas flow of $6.0 \mathrm{~L} / \mathrm{min}$, tidal volume of $8 \mathrm{ml} /$ $\mathrm{min}$, and respiratory rate of $12 / \mathrm{min}$.

The optimal cuff volume and minimal cuff volume were measured $10 \mathrm{~min}$ after the insertion of LMA. First, the cuff was deflated with a $50 \mathrm{ml}$ syringe using a three-way stopcock; this allowed the addition or removal of air from the cuff. The air was removed under a negative pressure until no movement of the plunger could be detected. For the measurements of maximal cuff pressure, the cuff was inflated according to the manufacturer's recommended maximal volume of air (40 ml for size $5,30 \mathrm{ml}$ for size 4) using a 50-ml syringe. The cuff was then deflated at a rate of $1.0 \mathrm{ml} / 15 \mathrm{~s}$ and the cuff volume was measured. The optimal cuff volume was measured at a cuff pressure of $60 \mathrm{cmH}_{2} \mathrm{O}$, with an airway peak pressure of $15 \mathrm{cmH}_{2} \mathrm{O}$ under a fresh gas flow of $\mathrm{O}_{2} 6.0 \mathrm{~L} / \mathrm{min}$. The minimal cuff volume and pressure were measured just before an audible leakage of air was detected around the nose and the mouth under the pressure mode ventilation (airway pressure of $15 \mathrm{cmH}_{2} \mathrm{O}$, respiration rate 12 beats/min, I : E ratio of $1: 2$ under a fresh gas flow of $\mathrm{O}_{2} 6.0 \mathrm{~L} / \mathrm{min}$ ). All the cuff pressure parameters were measured with an air-filled arterial line pressure transducer (BT4812-3, Biosensors, Singapore) connected to the monitor in the operating room. 


\section{Physical examination parameters}

Before the induction of anesthesia in the operating room, a physical examination of the patient's head and neck was performed to measure the following parameters: 1) body weight (kg) and 2) height ( $\mathrm{ml}$ ) of the patients were recorded at the initial hospital visit; 3) BMI $\left(\mathrm{kg} / \mathrm{m}^{2}\right)$ was calculated using the formula BMI = weight $(\mathrm{kg}) /$ height $\left.^{2}\left(\mathrm{ml}^{2}\right) ; 4\right)$ neck circumference $(\mathrm{cm})$ was measured immediately above the thyroid cartilage with flexible tape, and during the measurements, the patient was instructed to hold their head up and look straight ahead; 5) neck length (cm) was measured from mastoid tip to sternal notch with flexible tape, in the supine position; 6) thyro-mental distance $(\mathrm{cm})$ from the thyroid notch to the mental prominence was measured in neutral head position, in the supine position at the end of expiration and without swallowing; and 7) MMP used for evaluation of oropharynx, performed with the patient seated, their head held in a neutral position, mouth wide open, and tongue protruding to its maximal position.

\section{Statistical analysis}

Data were analyzed using Sigmaplot 12.3 (Systat Software
Inc., USA) and were reported as the mean \pm standard deviation unless otherwise indicated. Sample size was determined with the reference book that described the suitable sample size for regression analysis [12]. The regression analysis required at least 20 cases per independent variable. In our study, there were eight independent variables (patient sex and seven parameters from the physical examination); therefore, 160 patients were required for the study. We enrolled 170 patients to take into account the potential of loss of data during the study period. The relationships between the physical parameters were assessed using the Pearson correlation coefficient. In addition, stepwise multilinear regression analyses were performed. A P value of $<0.05$ was considered statistically significant.

\section{RESULTS}

A total of 170 patients were enrolled in the study (85 men and 85 women). One of the men and two of the women were excluded due to air leakage upon LMA insertion. There were no instances of LMA dislodgement, airway obstruction, or pulmonary aspiration during anesthesia. Data from the final 167 patients were included in the analysis (Fig. 1). Patient characteristics and physical parameters from head and neck

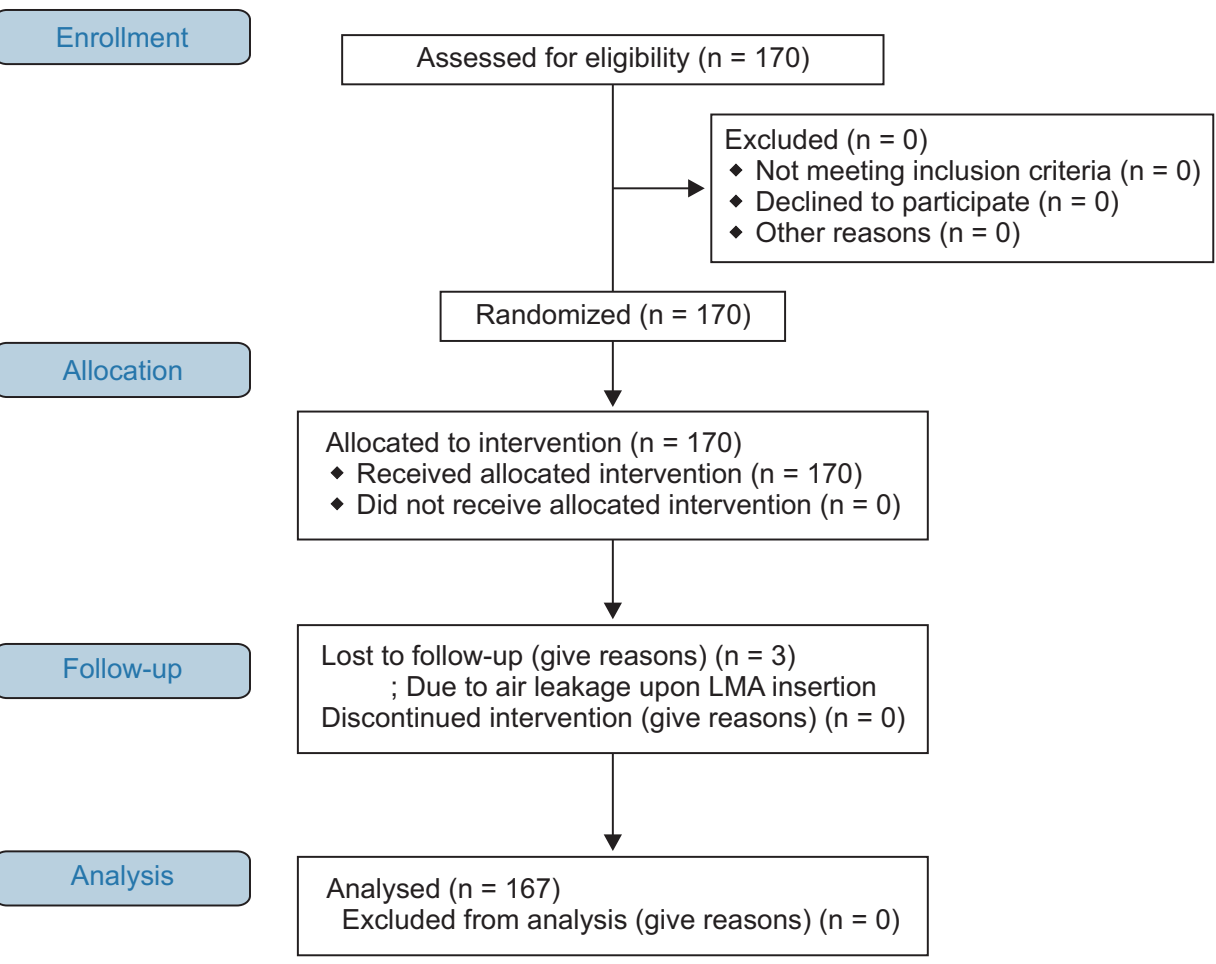

Fig. 1. CONSORT flow diagram. 
examinations according to patient sex are shown in Table 1.

The optimal cuff volume was correlated with height and neck length in men $(\mathrm{P}<0.01)$, but was not correlated with physical parameters in women (Table 2). The optimal and

Table 1. Patient Characteristics and Physical Parameters from Head and Neck Examinations, according to Patient Sex

\begin{tabular}{lcc}
\hline & Men $(\mathrm{n}=84)$ & Women $(\mathrm{n}=83)$ \\
\hline Age $(\mathrm{yr})$ & $37.7 \pm 14.3$ & $46.7 \pm 12.5$ \\
Height $(\mathrm{cm})$ & $174.3 \pm 6.3$ & $158.2 \pm 5.2$ \\
Weight $(\mathrm{kg})$ & $75.4 \pm 12.1$ & $58.5 \pm 8.7$ \\
Body mass index $\left(\mathrm{kg} / \mathrm{m}^{2}\right)$ & $24.8 \pm 3.5$ & $23.4 \pm 3.5$ \\
Neck circumference $(\mathrm{cm})$ & $39.5 \pm 2.8$ & $33.5 \pm 2.4$ \\
Neck length $(\mathrm{cm})$ & $17.4 \pm 1.4$ & $15.0 \pm 2.0$ \\
Thyro-mental distance $(\mathrm{cm})$ & $5.5 \pm 3.1$ & $5.5 \pm 1.0$ \\
Modified mallampati classification & \\
I & $30(35 \%)$ & $22(27 \%)$ \\
II & $30(35 \%)$ & $39(48 \%)$ \\
III & $21(25 \%)$ & $19(23 \%)$ \\
IV & $4(5 \%)$ & $2(2 \%)$ \\
\hline
\end{tabular}

Values are mean \pm SD or number of patients. minimal cuff volume has a positive correlation with the height and neck length of the patients, but the minimal cuff volume has a negative correlation with MMP in both sexes (P $<0.001$; Table 3, Fig. 2).

The regression equation (RE) to calculate the optimal cuff volume for men and women are as follows: $(1.2+[0.1 \times$ height $]+[0.5 \times$ neck length $])\left(\right.$ adjusted $\left.R^{2}=0.100\right)$. The REs to calculate the minimal cuff volume are as follows: for men $(-35.7+[0.25 \times$ height $]+[0.7 \times$ neck length $]-[4.1 \times \mathrm{MMP}])$ (adjusted $\left.\mathrm{R}^{2}=0.702\right)$; and for women $(-42.5+[0.27 \times$ height $]$ $+[0.75 \times$ neck length $]-[2.5 \times \mathrm{MMP}]),\left(\right.$ adjusted $\left.\mathrm{R}^{2}=0.603\right)$.

The mean value of the maximal cuff pressure was high at $>200 \mathrm{cmH}_{2} \mathrm{O}$ and of the minimal cuff pressure was low at $<$ $20 \mathrm{cmH}_{2} \mathrm{O}$. The mean value of the optimal cuff volume was $24.7 \mathrm{ml}$ for men and $15.9 \mathrm{ml}$ for women. The mean value of the minimal cuff volumes were $12.1 \mathrm{ml}$ for men and $7.1 \mathrm{ml}$ for women (Table 4).

Table 2. Correlations between the Optimal Laryngeal Mask Airway Cuff Volume and Parameters from the Physical Examination of the Head and Neck

\begin{tabular}{lcccc}
\hline & \multicolumn{2}{c}{ Men $(\mathrm{n}=84)$} & \multicolumn{2}{c}{ Women $(\mathrm{n}=83)$} \\
\cline { 2 - 5 } & Correlation coefficient & P value & Correlation coefficient & P value \\
\hline Height & 0.286 & $0.008^{*}$ & 0.070 & 0.527 \\
Weight & 0.082 & 0.458 & 0.091 & 0.416 \\
Body mass index & -0.044 & 0.687 & 0.060 & 0.590 \\
Neck circumference & 0.028 & 0.334 & 0.118 & 0.291 \\
Neck length & 0.321 & $0.003^{*}$ & -0.094 & 0.401 \\
Thyro-mental distance & 0.106 & 0.796 & -0.160 & 0.345 \\
Modified mallampati classification & 0.007 & 0.947 & -0.085 & 0.446 \\
\hline
\end{tabular}

*Statistically significant $(P<0.05)$.

Table 3. Correlations between the Minimal Laryngeal Mask Airway Cuff Volume and the Parameters from the Physical Examinations of the Head and Neck

\begin{tabular}{lcccc}
\hline & \multicolumn{2}{c}{ Men $(\mathrm{n}=84)$} & \multicolumn{2}{c}{ Women $(\mathrm{n}=83)$} \\
\cline { 2 - 5 } & Correlation coefficient & P value & Correlation coefficient & P value \\
\hline Height & 0.417 & $<0.001^{*}$ & $0.562^{*}$ & $<0.001^{*}$ \\
Weight & 0.040 & 0.719 & -0.068 & 0.545 \\
Body mass index & -0.158 & 0.149 & -0.320 & 0.003 \\
Neck circumference & -0.131 & 0.231 & -0.213 & 0.054 \\
Neck length & 0.379 & $<0.001^{*}$ & 0.428 & $<0.001^{*}$ \\
Thyro-mental distance & -0.085 & 0.442 & -0.209 & 0.060 \\
Modified mallampati classification & -0.728 & $<0.001^{*}$ & -0.545 & $<0.001^{*}$ \\
\hline
\end{tabular}

*Statistically significant $(P<0.05)$. 

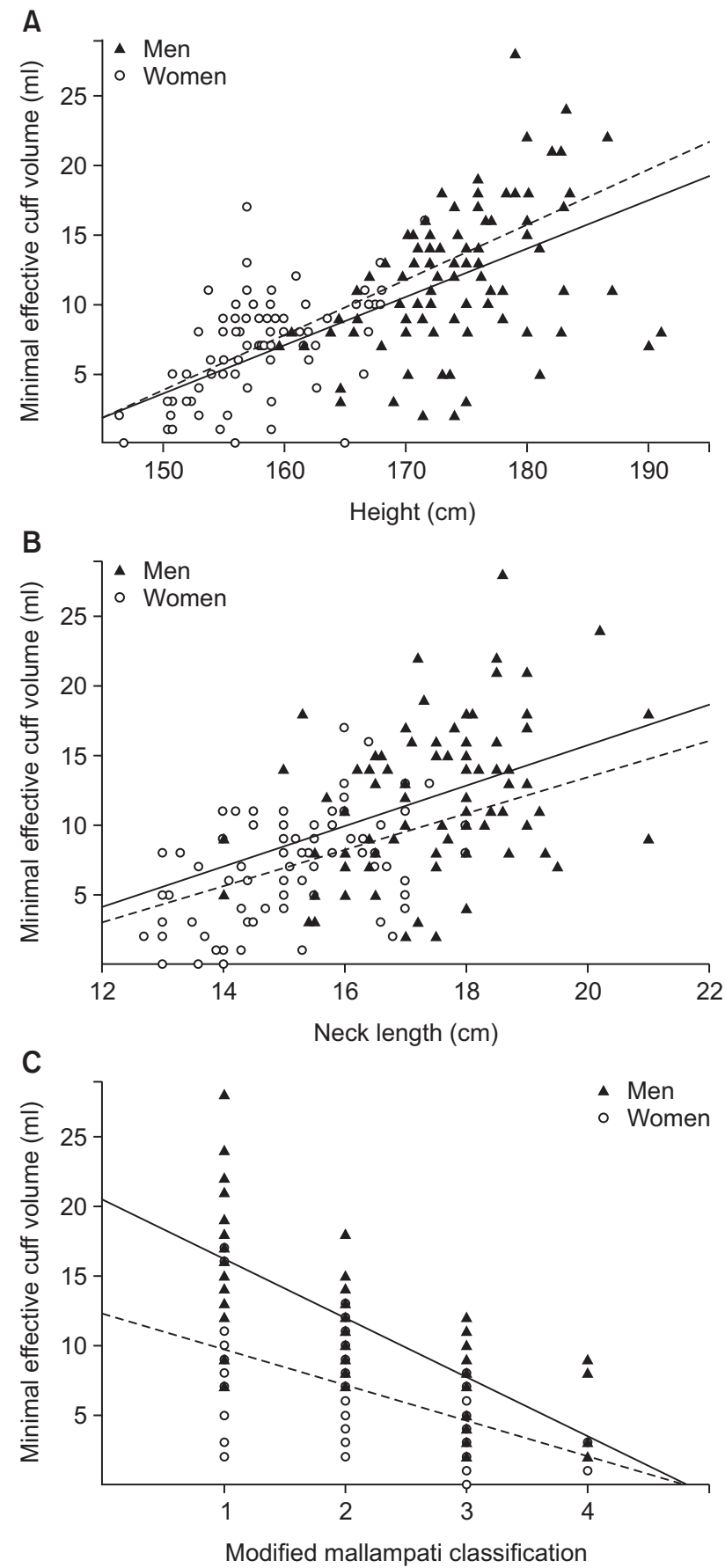

Fig. 2. Relationships between the minimal cuff volume and (A) patient height, (B) neck length, and (C) modified Mallampati classification. Height and the neck length exhibit a positive relationship with the optimal cuff volume, whereas modified Mallampati classification exhibits a negative relationship.

\section{DISCUSSION}

Our study investigated the correlation between the optimal or minimal LMA cuff volumes and the physical parameters
Table 4. Maximal, Optimal, and Minimal Laryngeal Mask Airway Cuff Pressures, with the Minimal Laryngeal Mask Airway Cuff Volume

\begin{tabular}{lcc}
\hline & Men $(\mathrm{n}=84)$ & Women $(\mathrm{n}=83)$ \\
\hline $\begin{array}{l}\text { Maximal cuff pressure } \\
\left(\mathrm{CmH}_{2} \mathrm{O}\right)\end{array}$ & $227.0 \pm 23.9$ & $274.2 \pm 23.8$ \\
$\begin{array}{l}\text { Optimal cuff volume at cuff } \\
\text { pressure } 60 \mathrm{cmH}_{2} \mathrm{O}(\mathrm{ml})\end{array}$ & $24.7 \pm 3.1$ & $15.9 \pm 2.0$ \\
$\begin{array}{l}\text { Minimal cuff volume }(\mathrm{ml}) \\
\text { Minimal cuff pressure }\end{array}$ & $12.1 \pm 5.2$ & $7.1 \pm 3.7$ \\
$\left(\mathrm{cmH}_{2} \mathrm{O}\right)$ & $12.0 \pm 12.7$ & $13.3 \pm 14.2$ \\
\hline
\end{tabular}

Values are mean \pm SD.

of patients, according to patient sex. The results of our study indicate that patient height, neck length, and MMP are good predictors of the optimal or minimal LMA cuff volumes. Especially, there was a high correlation in the equation for calculating the minimal LMA cuff volume, using patient height, neck length, and MMP.

The manufacturer's instruction manual for determining LMA size indicated a body weight-related selection (i.e., 50$70 \mathrm{~kg}$ for size 4 and $70-100 \mathrm{~kg}$ for size 5). However, in previous studies [9,10,13], a sex-related selection of LMA size (i.e., size 4 in women and size 5 in men) provided the optimal size by an ease of insertion, sufficient sealing effect, and satisfactory anatomical position of the LMA in patients. In our study, we investigated the correlations between LMA cuff volume and physical parameters with the selection of LMA size based on patient sex.

LMA is designed to fit the laryngeal part of the pharynx, and the proximal part of the cuff should be positioned caudal to the jaw and tonsils [11]. The cuff pressure of LMA exerted on the pharyngeal mucosa may result in potential morbidity. However, the exerted pressure of LMA cuff did not distribute evenly on the pharynx $[9,14]$, and the high pressure of LMA cuff maintained its shape on the pharynx, leading to mucosal ischemia with increased sealing effect [15]. Direct measurements of the exerted pressure on mucosa generally increase with increasing LMA cuff volume [15]. When the cuff is inflated according to the recommended maximal volume, the exerted pressure can exceed the capillary pressure [15]. Clinical data have shown a higher incidence of postoperative morbidities in adults in these situations [2-4]. The postoperative vulnerable ischemic site comprises the posterior pharyngeal wall by the LMA tube and the base of the tongue by 
the LMA cuff [15]. If the cuff is placed in the oral cavity, it may increase the risk of a sore throat or ischemic damage around the tongue. The serious complications associated with the use of LMA that have been reported include transient tongue cyanosis and neuro-paralysis in the lingual, hypoglossal, or recurrent laryngeal nerve [2-4]. Furthermore, increasing the cuff volume of LMA displaces the larynx anteriorly and results in the movement of the epiglottis into the bowel and deterioration of the fiberoptic view and gastric insufflation [16]. Therefore, an adjustment of the optimal or minimal LMA cuff volume may be essential and important for avoiding these complications.

Numerous other clinical trials have investigated the use of physical examination parameters for the predication of the cuff volume of an endotracheal tube, laryngeal tube, and obstructive sleep apnea grade [17-19]. Shibasaki et al. [17] estimated the optimal cuff volume of an endotracheal tube using the tracheal diameter and patient's height and age. In addition, Asai and Shingu [18] reported that the appropriate cuff volume of the laryngeal tube is correlated with the patient's height and weight. Furthermore, Frideman et al. [19] found that physical findings such as MMP, tonsil size, and BMI were strongly correlated with the severity of obstructive sleep apnea. In our study, we evaluated whether the physical parameters of patients could be used as predictors of the optimal or minimal LMA cuff volume. Therefore, predicting LMA cuff volume by physical parameters, and adopting the optimal or minimal cuff volume as guidelines, could be helpful in anesthetic practice. Our findings show that the minimal volume of LMA cuff correlated with patient height, neck length, and MMP, while the optimal volume of LMA cuff only correlated with the patient height and neck length. These results demonstrate stronger correlations between physical parameters and the minimal volume than the optimal cuff volume. The soft characteristic in the minimal volume is better able to fit into the variable contours of the pharynx than the tense characteristic in the optimal volume. According to the clinical results in our study, the greater the patient's height and neck length, the larger the cuff volume for the optimal LMA cuff pressure should be.

In our study, the maximal LMA cuff pressures according to the manufacturer's recommended maximal volume were found to exceed $200 \mathrm{cmH}_{2} \mathrm{O}\left(227.0 \mathrm{cmH}_{2} \mathrm{O}\right.$ in men and 274.2 $\mathrm{cmH}_{2} \mathrm{O}$ in women). Ideally, the LMA cuff should be inflated with the minimal cuff volume required to provide an effective pharyngeal seal [20]. Generally, the perfusion of the pharynx is reduced when mucosal pressure is increased over $60 \mathrm{mmHg}$ [1], and a cuff pressure below $60 \mathrm{cmH}_{2} \mathrm{O}$ not only reduces the risk of mucosal ischemia but also improves the seal around the LMA cuff $[20,21]$. An optimal LMA cuff pressure of $60 \mathrm{cmH}_{2} \mathrm{O}$ can provide an adequate pharyngeal seal above $15 \mathrm{cmH}_{2} \mathrm{O}$ of airway pressure under positive pressure ventilation in $93 \%$ of patients [11]. In our study, we found that the inflation of the LMA cuff to achieve a pharyngeal seal only required approximately one-half of the maximal recommended inflation volume $(24.7 \mathrm{ml}$ vs. $40 \mathrm{ml}$ for men, $15.9 \mathrm{ml}$ vs. $30 \mathrm{ml}$ for women).

The anatomy of the pharynx is known to vary according to patient sex $[9,22,23]$. In the study of Brimacombe and Keller [9], in the selection for LMA size based on patient sex, it was suggested that there were the differences in pharyngeal shape and compliance between men and women. Furthermore, Shigeta et al. [22] reported that men have a significantly longer oropharynx containing a larger soft tissue volume than women. In the present study, in contrast to the other results showing a strong correlation with physical parameters, the optimal cuff volume in women was not correlated with the physical parameters. The LMA cuff volume would be less variable in the smaller space of the oropharynx in women compared with the larger space in men. The surface of the LMA cuff may be more rigid than that of the minimal volume, and therefore the cuff volume may be less variable among oropharynx anatomical shapes and compliances. But in this present study, the number of patients was not calculated on the base of the statistical analysis for sex, so the interpretation of the results may be inappropriate.

This study had some limitations. First, we did not measure postoperative pharyngo-laryngeal complications; therefore, we could not determine whether the LMA cuff volume employed in our study reduced such complications. Second, we constructed the REs using data obtained from LMA classic ${ }^{\mathrm{TM}}$ with silicone. This REs may vary according to the type of LMA cuff material; therefore, the equation may not be applicable if another LMA device is utilized. Third, there may be some ethnic variability among patients, indicating that the results reported here may not be generalizable to other patient populations.

In conclusion, the cuff volume of the LMA can be better 
estimated by patient height, neck length, and MMP classification, according to patient sex. The equation for calculating of the minimal cuff volume shows a high correlation with patient height, neck length, and MMP.

\section{REFERENCES}

1. Seet E, Yousaf F, Gupta S, Subramanyam R, Wong DT, Chung F. Use of manometry for laryngeal mask airway reduces postoperative pharyngolaryngeal adverse events: a prospective, randomized trial. Anesthesiology 2010; 112: 652-7.

2. Wynn JM, Jones KL. Tongue cyanosis after laryngeal mask airway insertion. Anesthesiology 1994; 80: 1403.

3. Lowinger D, Benjamin B, Gadd L. Recurrent laryngeal nerve injury caused by a laryngeal mask airway. Anaesth Intensive Care 1999; 27: 202-5.

4. Nagai K, Sakuramoto C, Goto F. Unilateral hypoglossal nerve paralysis following the use of the laryngeal mask airway. Anaesthesia 1994; 49: 603-4.

5. Devitt JH, Wenstone R, Noel AG, O’Donnell MP. The laryngeal mask airway and positive-pressure ventilation. Anesthesiology 1994; 80: 550-5.

6. Wakeling HG, Butler PJ, Baxter PJ. The laryngeal mask airway: a comparison between two insertion techniques. Anesth Analg 1997; 85: 687-90.

7. Nandwani N, Fairfield MC, Krarup K, Thompson J. The effect of laryngeal mask airway insertion on the position of the internal jugular vein. Anaesthesia 1997; 52: 77-9.

8. Friedman M, Tanyeri H, La Rosa M, Landsberg R, Vaidyanathan K, Pieri S, et al. Clinical predictors of obstructive sleep apnea. Laryngoscope 1999; 109: 1901-7.

9. Brimacombe J, Keller C. Laryngeal mask airway size selection in males and females: ease of insertion, oropharyngeal leak pressure, pharyngeal mucosal pressures and anatomical position. $\mathrm{Br}$ J Anaesth 1999; 82: 703-7.

10. Berry AM, Brimacombe JR, McManus KF, Goldblatt M. An evaluation of the factors influencing selection of the optimal size of laryngeal mask airway in normal adults. Anaesthesia 1998; 53: 565-70.
11. Brimacombe JR, Brain AIJ, Berry AM. The Laryngeal Mask Instruction Manual for Anaesthesia. Henlye-on-Thames, Intravent research Ltd. 1999, pp 1-17.

12. Feinstein AR. Multivariable Analysis: An Introduction. New Haven, Yale University Press. 1996, pp 68-77.

13. Asai T, Murao K, Yukawa H, Shingu K. Re-evaluation of appropriate size of the laryngeal mask airway. Br J Anaesth 1999; 83: 4789.

14. Marjot R. Pressure exerted by the laryngeal mask airway cuff upon the pharyngeal mucosa. Br J Anaesth 1993; 70: 25-9.

15. Brimacombe J, Keller C. A comparison of pharyngeal mucosal pressure and airway sealing pressure with the laryngeal mask airway in anesthetized adult patients. Anesth Analg 1998; 87: 1379-82.

16. Keller C, Pühringer F, Brimacombe JR. Influence of cuff volume on oropharyngeal leak pressure and fibreoptic position with the laryngeal mask airway. Br J Anaesth 1998; 81: 186-7.

17. Shibasaki M, Nakajima Y, Shime N, Sawa T, Sessler DI. Prediction of optimal endotracheal tube cuff volume from tracheal diameter and from patient height and age: a prospective cohort trial. J Anesth 2012; 26: 536-40.

18. Asai T, Shingu K. Appropriate cuff volumes of the Laryngeal Tube. Anaesthesia 2005; 60: 486-9.

19. Friedman M, Tanyeri H, La Rosa M, Landsberg R, Vaidyanathan K, Pieri S, et al. Clinical predictors of obstructive sleep apnea. Laryngoscope 1999; 109: 1901-7.

20. Brimacombe J, Keller C, Pühringer F. Pharyngeal mucosal pressure and perfusion: a fiberoptic evaluation of the posterior pharynx in anesthetized adult patients with a modified cuffed oropharyngeal airway. Anesthesiology 1999; 91: 1661-5.

21. Asai T, Brimacombe J. Review article: cuff volume and size selection with the laryngeal mask. Anaesthesia 2000; 55: 1179-84.

22. Shigeta Y, Ogawa T, Venturin J, Nguyen M, Clark GT, Enciso R. Gender- and age-based differences in computerized tomographic measurements of the orophaynx. Oral Surg Oral Med Oral Pathol Oral Radiol Endod 2008; 106: 563-70.

23. Jun JH, Kim JH, Baik HJ, Kim YJ, Yun DG. Analysis of predictive factors for difficult ProSeal laryngeal mask airway insertion and suboptimal positioning. Anesth Pain Med 2013; 8: 271-8. 